\title{
A Moran's IAutocorrelation and Hot Spot Analysis for Identifying and Predicting Diarrheal Disease Cases around Sixty-Seven Community Wells in West Pokot County, Kenya
}

\author{
Ryan C Graydon*, Samuel Alao and Benjamin G Jacob
}

Department of Global Health, College of Public Health, University of South Florida, Tampa, USA

\begin{abstract}
Water, sanitation, and hygiene (WASH) infrastructure is crucial to the health of every community. Globally, rural communities disproportionately lack improved drinking water and sanitation facilities compared to urban communities. West Pokot County, Kenya has a population of 512,690 people of which $91.7 \%$ live in rural areas. The Pokot people, the main people group residing in West Pokot County, depend on communal wells, rivers, and other surface water sources presenting the opportunity to consume pathogens and induce diarrheal diseases. Harvester's International works with Pokot leaders to install community wells to provide an improved drinking water alternative to surface water in order to break the diarrheal disease transmission cycle. Community health epidemiological and spatial data from 67 communities in West Pokot County were assessed using autocorrelation and hot spot analysis in GIS software to identify geographical locations of reported cases of diarrheal diseases and to predict diarrheal disease cases across the entire county. The hot spot analysis revealed five hot spots and one cold spot and predicted additional hot spots in the southwest region of the county. This map is useful to target the specific locations for public health interventions to control and eliminate diarrheal diseases in West Pokot County. Future studies should include more spatial data points to improve the validity and reliability of the prediction map.
\end{abstract}

Keywords: Diarrhea; Waterborne disease; Community wells; Spatial analysis; West Pokot County; Kenya; Africa

\section{Introduction}

At the conclusion of the Millennium Development Goals in 2015, 663 million people still lacked an improved drinking water source and 2.4 billion people lacked access to an improved sanitation facility worldwide. Disparities were revealed as 8 of 10 people who lack an improved drinking water source and 7 of 10 people who lack an improve $d$ sanitation facility live in rural areas [1]. The health effects of this lack of water, sanitation, and hygiene (WASH) infrastructure are staggering. Inadequate WASH causes a variety of diseases and disabilities including diarrheal disease from the ingestion of the minimum quantity of pathogenic organisms in drinking water. Inadequate WASH was estimated to be the cause of 842,000 diarrheal deaths globally representing $58 \%$ of diarrheal diseases in 2012 [2], which was approximately 2,300 deaths per day. Nine of 10 diarrheal deaths occur in children with the significant majority of deaths located in developing countries [3]. Persistent diarrhea among children is associated with malnutrition, cognitive impairment [4,5], and an increased risk of developing obesity later in life [6].

In many areas of rural Kenya, improved drinking water sources and improved sanitation facilities are inadequate [1]. Therefore, rural village communities depend on untreated water from communal wells, rivers, and other surface water sources to meet their needs presenting the opportunity to consume pathogens and induce disease. Geographic information system (GIS) has been used to map the spread of diseases, including diarrheal diseases, as part of surveillance and control strategies [7-10]. Unfortunately, despite endemic diarrheal diseases throughout every Kenyan county, the application of GIS technologies to assist in the control and elimination of these diseases in Kenya is sparse in published literature and has not been reported for West Pokot County. The purpose of this research is to identify the reported cases of diarrheal diseases and to predict hot spots for other cases of diarrheal diseases in West Pokot County, Kenya using spatial autocorrelation and hot spot analysis.

\section{Materials and Methods}

\section{Study area and population}

West Pokot County is located in Northwest Kenya along the Ugandan border (Figure 1), and is one of 47 counties in Kenya under the new dispensation of county governments that went into effect after the general election of March 2013 [11]. The capital of West Pokot County is Kapenguria. The geographical area is $8,418.2 \mathrm{~km}^{2}$ and reported a population of 512,690 people during the 2009 census (Figure 2).

The Pokot people (Figure 3) live in West Pokot County, in neighboring Baringo County, and in the Pokot District of Eastern Karamoja Region in Uganda. They speak Pökoot, a language of the Southern Nilotic language family, which is similar to the Marakwet, Nandi, Tugen, and other tongues of the Kalenjin grouping. According to the 2009 census, there were an estimated 500,000 Pökoot speakers in West Pokot County. The Pokot's political system is governed through a graduated age system with elders given tremendous status and respect [11].

The people of West Pokot County live mostly in rural areas in much greater proportion than Kenya's average (Figure 4) [12]. The WASH

*Corresponding author: Ryan C Graydon, Department of Global Health, College of Public Health, University of South Florida, Tampa, USA, Tel: 8139749784 ; E-mail: rgraydon@health.usf.edu

Received November 04, 2016; Accepted November 25, 2016; Published November 28, 2016

Citation: Graydon RC, Alao S, Jacob BG (2016) A Moran's I Autocorrelation and Hot Spot Analysis for Identifying and Predicting Diarrheal Disease Cases around Sixty-Seven Community Wells in West Pokot County, Kenya. J Remote Sensing \& GIS 5: 182. doi: 10.4182/2469-4134.1000182

Copyright: (c) 2016 Graydon RC, et al. This is an open-access article distributed under the terms of the Creative Commons Attribution License, which permits unrestricted use, distribution, and reproduction in any medium, provided the original author and source are credited. 


\section{Location of West Pokot County, Kenya, Africa}

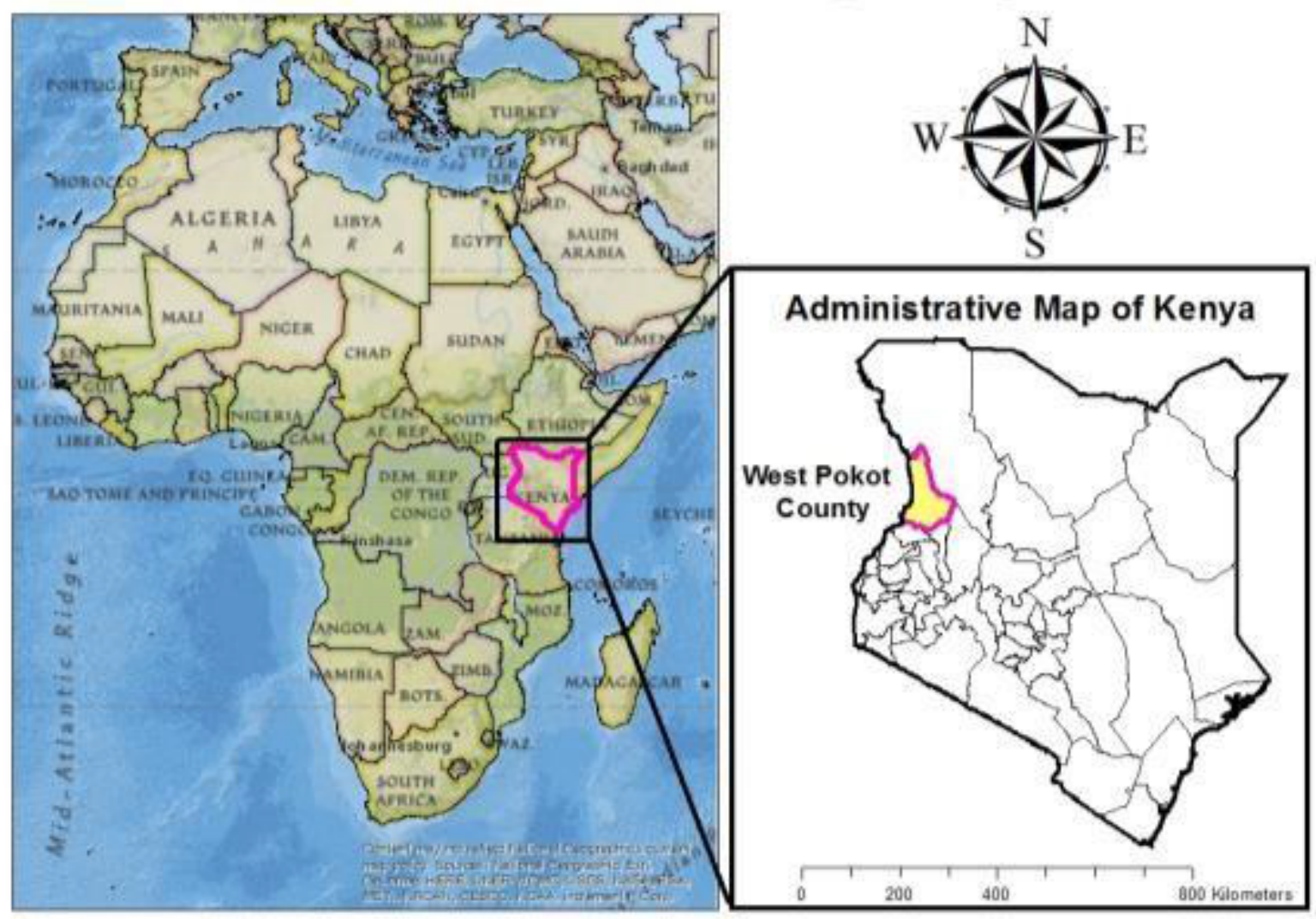

Figure 1: Location of West Pokot County, Kenya, Africa (This map represents the geographical location of the study site).

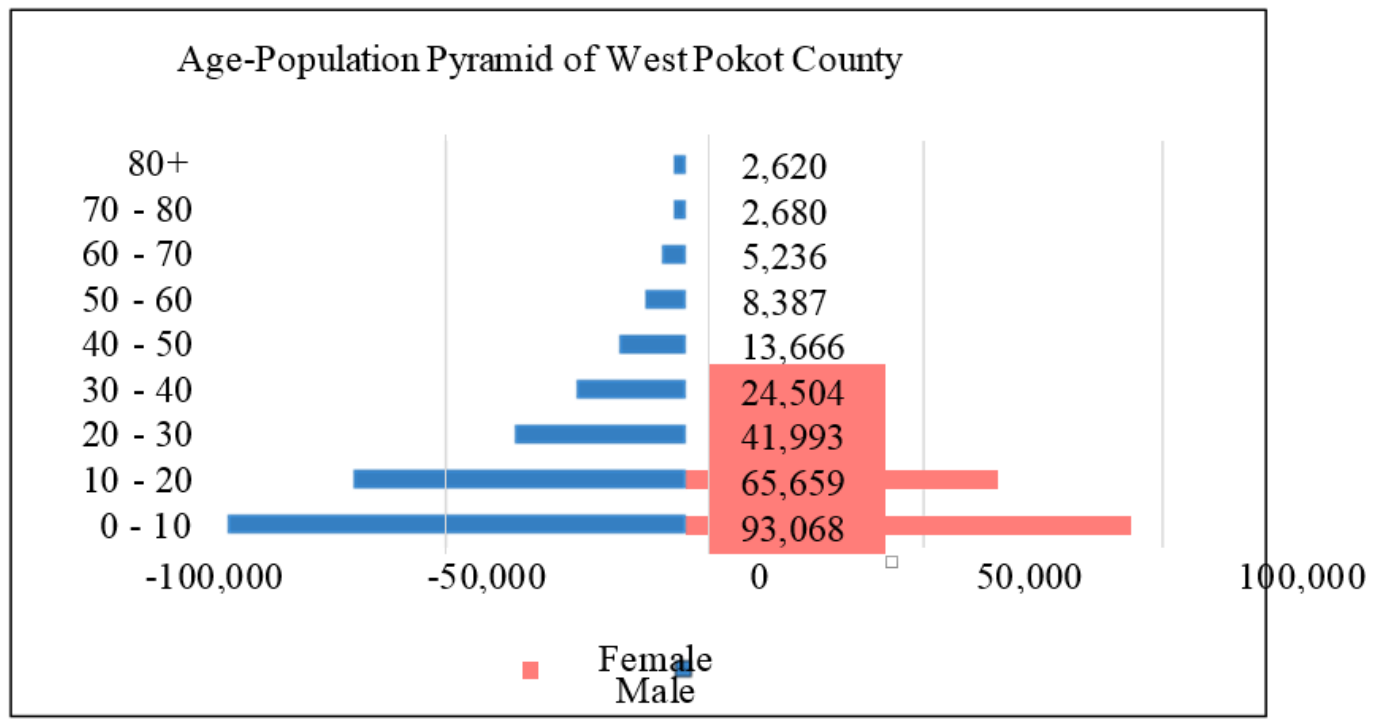

Figure 2: Age-Population Pyramid of West Pokot County (This graph presents the population and age bracket as reported by the Kenya National Bureau of Statistics from 2009 census data). 
Citation: Graydon RC, Alao S, Jacob BG (2016) A Moran's I Autocorrelation and Hot Spot Analysis for Identifying and Predicting Diarrheal Disease Cases around Sixty-Seven Community Wells in West Pokot County, Kenya. J Remote Sensing \& GIS 5: 182. doi: 10.4182/2469-4134.1000182

Page 3 of 7

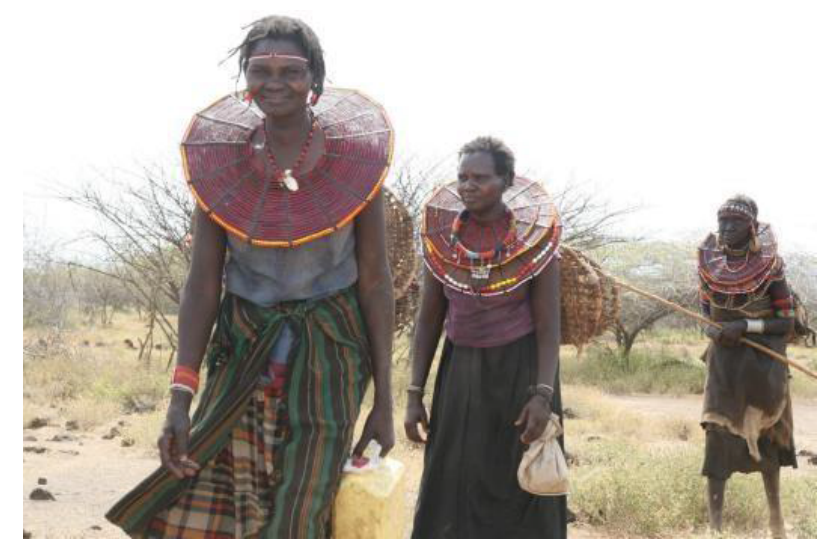

Figure 3: Pokot women walking through pastureland wearing their iconic ornate beadwork.

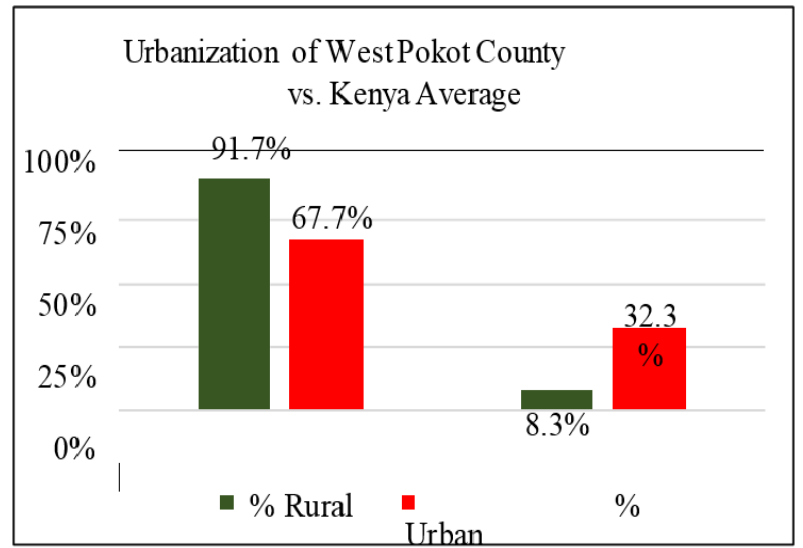

Figure 4: Urbanization of West Pokot County vs. Kenya Average (This graph presents data gathered from the 2009 census by the Kenya National Bureau of Statistics)

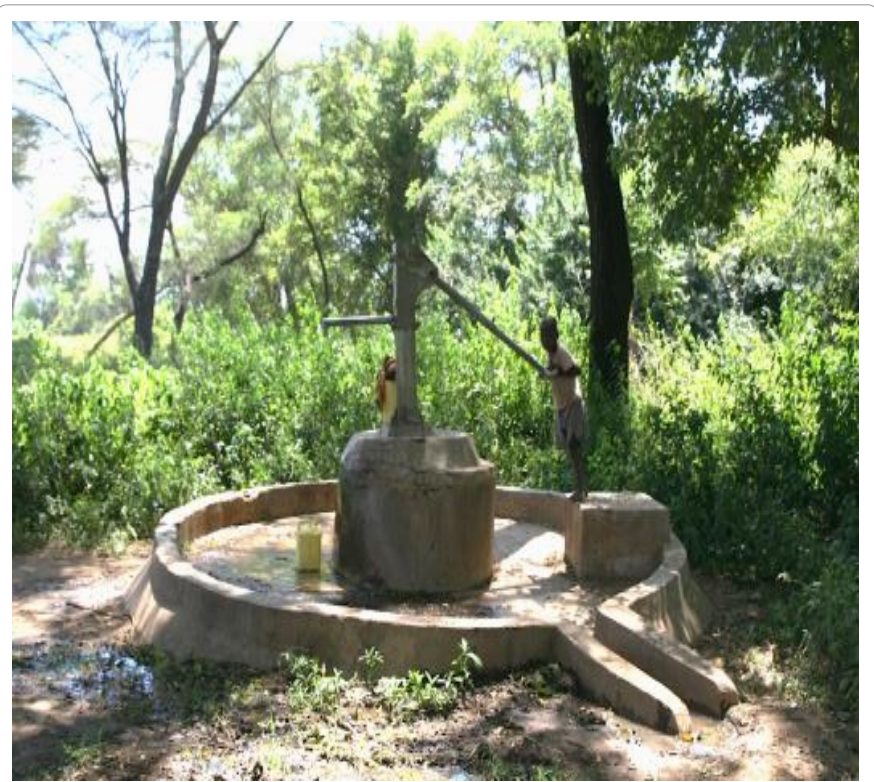

Figure 5: A Pokot child fills a couple jugs with water from a community well installed by Harvester's International. infrastructure in these rural agrovillages is generally inadequate. Community wells, boreholes, and other surface water sources are commonly used (Figure 5). For sanitation, latrines are used however open defecation is still a common practice in many communities (Figure 6). Livestock (e.g., cattle and goats) are an important agricultural and economic asset of Pokot culture and often graze near human habitations and water sources (Figure 7) [13]. The close proximity of livestock to Pokot drinking water sources is a potential source of fecal contamination and enteric pathoge ns.

\section{Data collection and classification of diarrheal diseases}

Community data was provided by Harvester's International, a nonprofit organization based in South Carolina that works with indigenous Pokot leaders to install community wells and other development initiatives. Surveys were employed between June and September 2014 in communities where wells were installed recording well GPS coordinates and function as well as community health information including population and symptom-based disease cases. Data from 85 communities was provided of which 67 communities are in West Pokot County. Amoebiasis, cholera, dysentery, and typhoid were included in the reports and classified as diarrheal diseases for the purpose of this study.

\section{Cases of diarrheal disease in West Pokot County}

For children under the age of five, West Pokot County reported 14,973 cases of diarrheal diseases in 2012, which was $1.2 \%$ of Kenya's total (Table 1) [14]. From the data collected by Harvester's International in West Pokot County, 645 cases of diarrheal diseases were reported among the 249,965 residents of the 67 rural communities yielding a point prevalence of 2.58 cases per 1,000 residents (Table 2) [13].

\section{Analytical tools and procedures}

ArcMap GIS (Esri Inc., v.10.3, Redlands, CA) was used to generate maps. Spatial autocorrelation (Global Moran's I) and Hot Spot Analysis (Getis-Ord $\mathrm{Gi}^{*}$ ) were employed to assess level of significance of diarrheal disease cases around each community well installed by Harvester's International and to predict hot and cold spots across West Pokot County. Spatial autocorrelation was set to aggregate features within five kilometers. Hot Spot Analysis forms analysis based on case count and does not account for population or prevalence statistics.

\section{Results}

As illustrated in Figure 8, there are five hot spots of cases of diarrhea, one spot at $99 \%$ confidence and the other four spots at $95 \%$ confidence. There is only one cold spot, which was at $90 \%$ confidence. The prediction model has a high Z-value of 2.96 concentrated in the southwest region of the county and a low Z-value of -1.56 mostly located in the south-central and northwest regions of the county.

\begin{tabular}{|c|c|c|c|}
\hline & West Pokot County & Kenya & \% of Kenya Total \\
\hline Cholera & 2 & 95 & $2.10 \%$ \\
\hline Diarrhea & 14,752 & $11,76,949$ & $1.30 \%$ \\
\hline Dysentery & 219 & 26,537 & $0.80 \%$ \\
\hline Typhoid & 1,372 & 29,635 & $4.60 \%$ \\
\hline Total & 14,973 & $12,03,581$ & $1.20 \%$ \\
\hline
\end{tabular}

Table 1: Diarrheal Disease Cases in Patients Below Five Years of Age in 2012 [12]. 
Citation: Graydon RC, Alao S, Jacob BG (2016) A Moran's I Autocorrelation and Hot Spot Analysis for Identifying and Predicting Diarrheal Disease Cases around Sixty-Seven Community Wells in West Pokot County, Kenya. J Remote Sensing \& GIS 5: 182. doi: 10.4182/2469-4134.1000182

Page 4 of 7

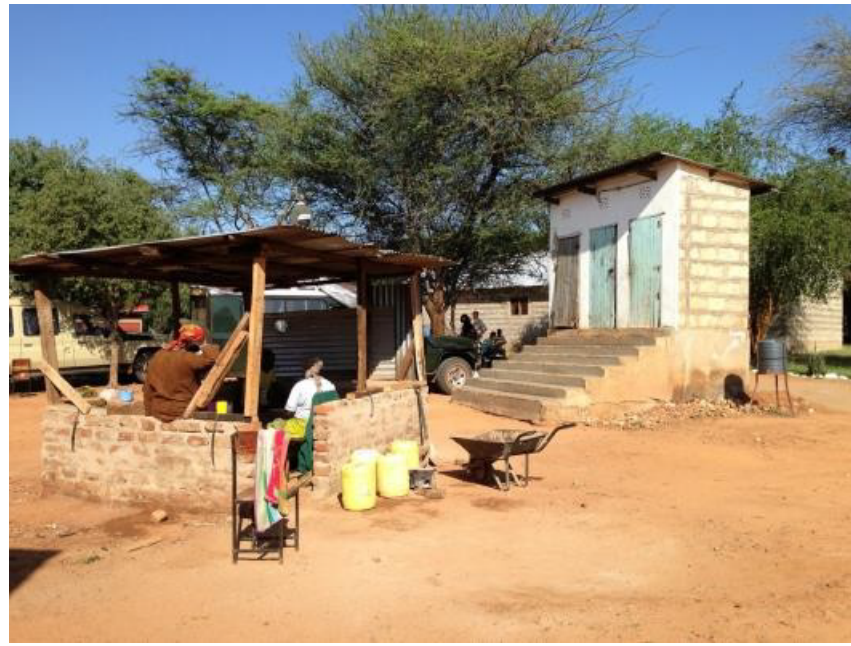

Figure 6: Pokot women sitting in a covered area with an elevated latrine to the right.

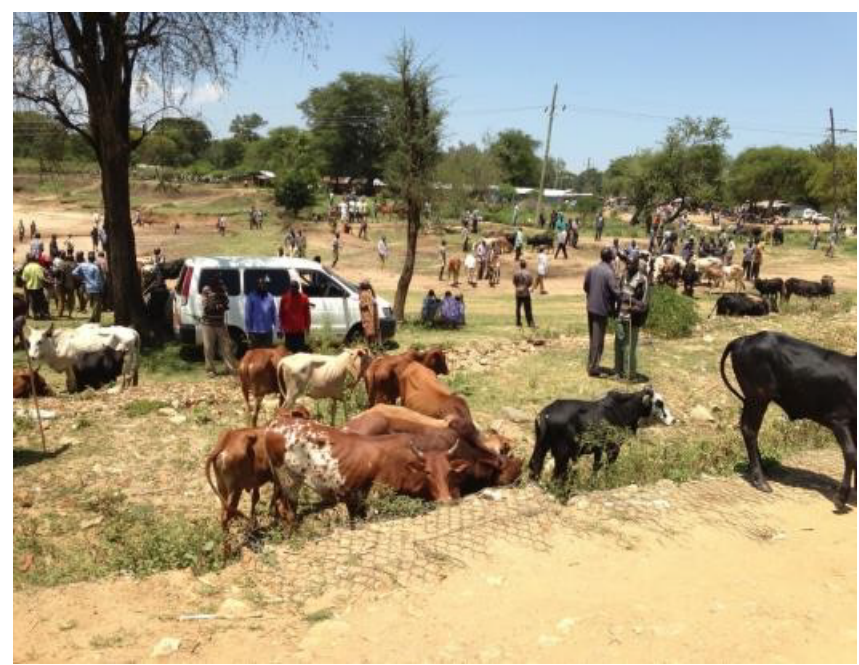

Figure 7: Pokot cattle grazing among community members near a river (left of frame).

\section{Discussion and Conclusions}

Using epidemiological and spatial data with GIS analysis, the results illustrated in Figure 8 reveal key areas of public health interest and intervention. The hot spot analysi s presents the locations where cases of diarrheal diseases are most prevalent. These locations should be given priority for control and elimination interventions to improve public health. Further assessment at each of these locations would be in order to determine the specific diarrheal disease and thus appropriate control and elimination strategies.

The prediction model illustrates the potential hot and cold spots of diarrheal disease across West Pokot County. This model appears to represent the data well as 9 of the top 10 locations of diarrheal disease cases are in red areas, which are predicted to be hot spots. However, the community of Samor, which had the sixth most diarrheal disease cases, is located in an area predicted as a cold spot. This is likely due to the relatively low number of spatial data points. In similar hot spot analyses $[7,8,10]$, hundreds to thousands of spatial data points were used in smaller geographical areas to illustrate disease case predictions. Our data set only had 67 spatial data points in West Pokot County, which is a limitation. However, this prediction model should be used as a priority guide to assist in the decision of which communities to target next. We recommend adding future community pidemiological assessment data to this prediction model to improve its reliability and validity for future intervention decision making.

The feasibility of adding to or replicating these models in the field is high because purchasing GIS band data was not required. The base maps and GIS tools were all included in the ArcGIS software package. Therefore, it is possible for a public health agency with limited resources to be able to make these models to identify and predict disease cases to inform their control and elimination interventions.

In summary, the purpose of this research was to identify the reported cases of diarrheal diseases and to predict hot and cold spots for other cases of diarrheal diseases in West Pokot County, Kenya using GIS spatial analysis. Figure 8 illustrates both the hot and cold spot trends based on the reported cases of diarrheal diseases from Harvester's International and the prediction of the locations of other diarrheal disease cases across the entire county. However, the validity and reliability of this map may be confoundi ng due to the small number of data points to form the prediction. To improve prediction

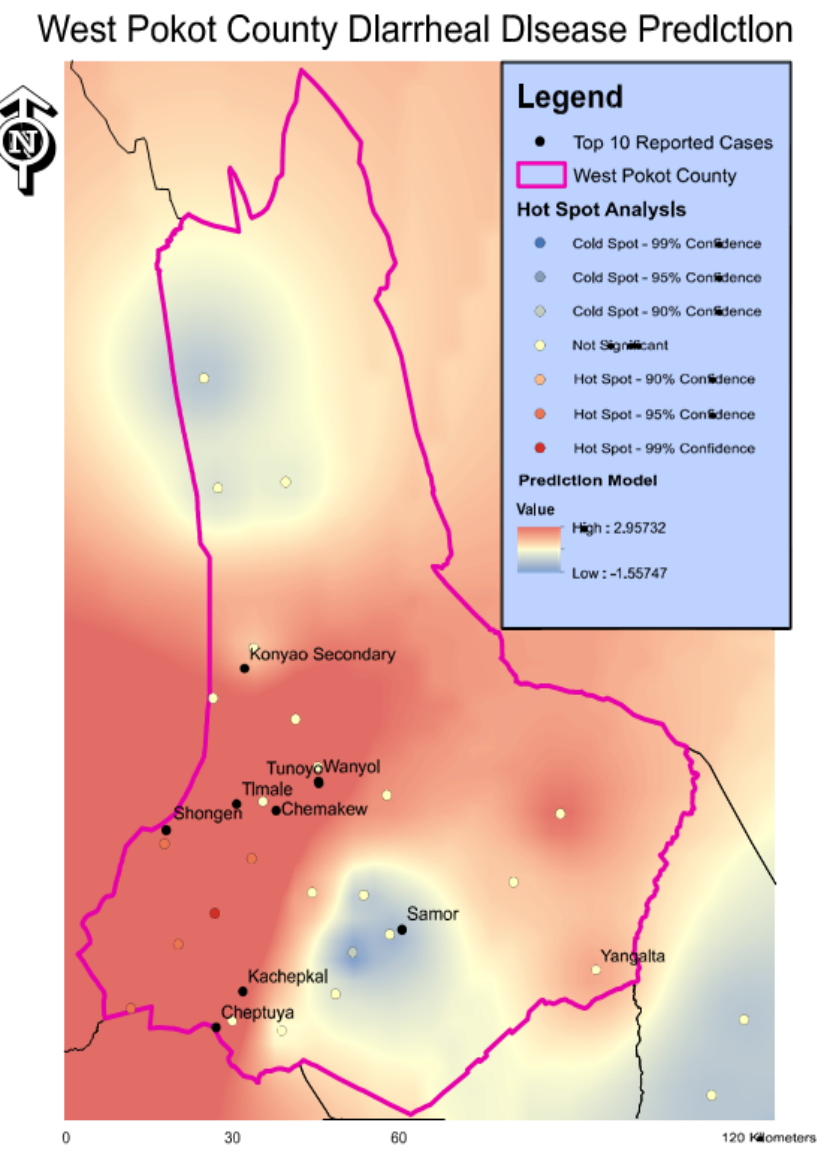

Figure 8: West Pokot County Diarrheal Disease Prediction (This map demonstrates the hot and cold spots of diarrheal disease cases and illustrates the prediction of diarrheal disease cases across the entire county. The communities with the 10 most reported cases of diarrheal diseases are also displayed). 
Citation: Graydon RC, Alao S, Jacob BG (2016) A Moran's I Autocorrelation and Hot Spot Analysis for Identifying and Predicting Diarrheal Disease Cases around Sixty-Seven Community Wells in West Pokot County, Kenya. J Remote Sensing \& GIS 5: 182. doi: 10.4182/2469-4134.1000182

Page 5 of 7

\begin{tabular}{|c|c|c|c|c|}
\hline Site Name & Assessment Date & Diarrhea Cases & Total People & Prevalence per 1000 \\
\hline Kachepkai & 08-Jul-14 & 70 & 976 & 71.72 \\
\hline Shongen & 24-Jun-14 & 46 & 1,500 & 30.67 \\
\hline Tunoyo & 09-Jul-14 & 38 & 1,698 & 22.38 \\
\hline Konyao Secondary & 26-Jun-14 & 30 & 750 & 40 \\
\hline Cheptuya & 27-Aug-14 & 25 & 9,500 & 2.63 \\
\hline Samor & 10-Jul-14 & 20 & 2,760 & 7.25 \\
\hline Chemakew & 29-Aug-14 & 20 & 6,200 & 3.23 \\
\hline Timale & 01-Sep-14 & 19 & 1,253 & 15.16 \\
\hline Yangaita & 24-Jul-14 & 18 & 8,200 & 2.2 \\
\hline Wanyoi & 09-Jul-14 & 15 & 4,220 & 3.55 \\
\hline Kapblakun & 21-Jul-14 & 14 & 10,600 & 1.32 \\
\hline Pole Highway & 23-Jul-14 & 12 & 2,000 & 6 \\
\hline Sawil & 24-Jul-14 & 12 & 2,050 & 5.85 \\
\hline Kalukuna & 01-Sep-14 & 12 & 2,150 & 5.58 \\
\hline Kodomuch & 01-Sep-14 & 12 & 3,100 & 3.87 \\
\hline Chemulunjo & 23-Jul-14 & 12 & 4,570 & 2.63 \\
\hline Kopeyon & 01-Sep-14 & 11 & 560 & 19.64 \\
\hline Father Leo Staples & 24-Jul-14 & 11 & 620 & 17.74 \\
\hline Kakwomeses & 24-Jul-14 & 11 & 2,700 & 4.07 \\
\hline Cheptuwoketo & 23-Jul-14 & 11 & 3,200 & 3.44 \\
\hline Riwo & 23-Jul-14 & 11 & 7,600 & 1.45 \\
\hline Naumaa & 27-Jun-14 & 10 & 4,300 & 2.33 \\
\hline Chepturu & 03-Sep-14 & 10 & 6,990 & 1.43 \\
\hline Mbaru & 27-Jun-14 & 10 & 8,090 & 1.24 \\
\hline Kauriong & 27-Jun-14 & 9 & 495 & 18.18 \\
\hline Kitelakapel & 18-Jul-14 & 9 & 3,800 & 2.37 \\
\hline Ngengechwo & 30-Aug-14 & 8 & 2,200 & 3.64 \\
\hline Lokna & 09-Jul-14 & 8 & 3,100 & 2.58 \\
\hline Chesawach & 16-Jul-14 & 8 & 3,400 & 2.35 \\
\hline Runo AIC & 24-Jul-14 & 7 & 1,300 & 5.38 \\
\hline Cherangan Community & 25-Jun-14 & 7 & 1,370 & 5.11 \\
\hline Napawoi & 28-Aug-14 & 7 & 1,700 & 4.12 \\
\hline Chepuyal Girls & 17-Jul-14 & 6 & 700 & 8.57 \\
\hline Rukei & 09-Jul-14 & 6 & 4,400 & 1.36 \\
\hline Katumkale & 26-Jun-14 & 6 & 8,020 & 0.75 \\
\hline Chepuyal Boys & 17-Jul-14 & 5 & 1,460 & 3.42 \\
\hline Murpus & 10-Jul-14 & 5 & 2,200 & 2.27 \\
\hline Chepuyal Community & 17-Jul-14 & 5 & 2,400 & 2.08 \\
\hline Merur & 09-Jul-14 & 5 & 5,650 & 0.88 \\
\hline Muruebong & 14-Jul-14 & 5 & 7,500 & 0.67 \\
\hline
\end{tabular}


Citation: Graydon RC, Alao S, Jacob BG (2016) A Moran's I Autocorrelation and Hot Spot Analysis for Identifying and Predicting Diarrheal Disease Cases around Sixty-Seven Community Wells in West Pokot County, Kenya. J Remote Sensing \& GIS 5: 182. doi: 10.4182/2469-4134.1000182

Page 6 of 7

\begin{tabular}{|c|c|c|c|c|}
\hline Pusian & 22-Jul-14 & 5 & 8,100 & 0.62 \\
\hline Atacha & 16-Jul-14 & 5 & 8,400 & 0.6 \\
\hline Tapadany & 07-Jul-14 & 4 & 1,000 & 4 \\
\hline Lokarkar & 02-Sep-14 & 4 & 1,320 & 3.03 \\
\hline Nakwangamoru & 16-Jul-14 & 4 & 1,950 & 2.05 \\
\hline Kaisa & 02-Sep-14 & 4 & 2,250 & 1.78 \\
\hline Kaplelack-Koror & 27-Aug-14 & 4 & 2,500 & 1.6 \\
\hline Kaa-ptuken & 27-Jun-14 & 4 & 2,900 & 1.38 \\
\hline Pser & 27-Aug-14 & 4 & 4,900 & 0.82 \\
\hline Kauriong Community & 27-Jun-14 & 4 & 9,300 & 0.43 \\
\hline Kakoron & 16-Jul-14 & 3 & 1,400 & 2.14 \\
\hline Tirokow & 02-Sep-14 & 3 & 2,100 & 1.43 \\
\hline Chepareria Market & 22-Jul-14 & 3 & 3,500 & 0.86 \\
\hline Chepkopegh & 10-Jul-14 & 3 & 3,950 & 0.76 \\
\hline Kishuanet & 08-Jul-14 & 3 & 4,200 & 0.71 \\
\hline Milimani/Bendera & 28-Aug-14 & 2 & 440 & 4.55 \\
\hline Plelkan & 02-Sep-14 & 2 & 953 & 2.1 \\
\hline Lokotetwo & 29-Aug-14 & 2 & 1,400 & 1.43 \\
\hline Konyao (St. Dorcas) & 01-Sep-14 & 2 & 1,550 & 1.29 \\
\hline Kalokiru & 16-Jul-14 & 2 & 1,850 & 1.08 \\
\hline Nangorotum & 27-Aug-14 & 2 & 1,900 & 1.05 \\
\hline Nakwapuo & 07-Jul-14 & 2 & 2,000 & 1 \\
\hline Katukumwok & 26-Jul-14 & 2 & 2,850 & 0.7 \\
\hline Napitiro & 25-Jun-14 & 2 & 7,000 & 0.29 \\
\hline Murunyangai & 26-Jun-14 & 2 & 9,000 & 0.22 \\
\hline Tomoi & 29-Aug-14 & 1 & 1,820 & 0.55 \\
\hline Ngengechwo & 07-Jul-14 & 1 & 16,150 & 0.06 \\
\hline Total & & 645 & $2,49,965$ & 2.58 \\
\hline
\end{tabular}

Table 2: Reported Cases of Diarrheal Disease in West Pokot County.

of hot spots especially in a large geographical area like West Pokot County, more data points is recommended for future studies.

\section{Acknowledgements}

We would like to give our sincere gratitude to Lucarelli $\mathrm{J}$ from Harvester's Internati o nal for graciously sharing the data and photos of their work with the Pokot people in West Pokot County and the surrounding counties. Your willingness to share and the quality of your work is greatly appreciated.

\section{References}

1. UNICEF \& WHO (2015) Progress on Sanitation and Drinking Water: 2015 Update and MDG Assessment. United States of America.

2. Prüss-Ustün A, Bartram J, Clasen T, Colford JM, Cumming O, et al. (2014) Burden of disease from inadequate water, sanitation and hygiene in low-and middle-income settings: a retrospective analysis of data from 145 countries. Trop Med Intl Health 19: 894-905.

3. Ashbolt NJ (2004) Microbial contamination of drinking water and disease outcomes in developing regions. Toxicology 198: 229-238.

4. Ferdous F, Das SK, Ahmed S, Farzana FD, Latham JR, et al. (2013) Severity of diarrhea and malnutrition among under five-year-old children in rural Bangladesh. Am J Trop Med Hyg 89: 223-228.

5. Hasanain FG, Jamsiah M, Zaleha MI, Azmi M, Tamil MA (2012) Association between drinking water sources and diarrhea with Malnutrition among kindergarten's children in Baghdad city, Iraq. Malaysian Journal of Public Health Medicine 12: 45-48.

6. Guerrant RL, DeBoer MD, Moore SR, Scharf RJ, Lima AA (2013) The impoverished gut-a triple burden of diarrhoea, stunting and chronic disease. Nat Rev Gastroenterol Hepatol 10: 220-229.

7. Hanna-Attisha M, LaChance J, Sadler RC, Champney Schnepp A (2016) Elevated blood lead levels in children associated with the Flint drinking water crisis: a spatial analysis of risk and public health response. Am J Public Health 106: $283-290$.

8. Bessong PO, Odiyo JO, Musekene JN, Tessema A (2009) Spatial distribution of diarrhoea and microbial quality of domestic water during an outbreak of diarrhoea in the Tshikuwi community in Venda, South Africa. J Health Popul Nutr 27: 652-659.

9. Jacob BG, Novak RJ, Toe LD, Sanfo M, Griffith DA, et al. (2013) Validation of a remote sensing model to identify simulium damnosum sl Breeding sites in Sub-Saharan Africa. PLoS Negl Trop Dis 7: e2342. 
Citation: Graydon RC, Alao S, Jacob BG (2016) A Moran's I Autocorrelation and Hot Spot Analysis for Identifying and Predicting Diarrheal Disease Cases around Sixty-Seven Community Wells in West Pokot County, Kenya. J Remote Sensing \& GIS 5: 182. doi: 10.4182/2469-4134.1000182

10. Njemanze PC, Anozie J, Ihenacho JO, Russell MJ, Uwaeziozi AB (1999) Application of risk analysis and geographic information system technologies to the prevention of diarrheal diseases in Nigeria. Am J Trop Med Hyg 61: $356-360$
11. (2016) County Government of West Pokot.

12. ICT Authority (2016) Kenya Open Data Portal.

13. Lucarelli J (2016) GIS Mapping for Well Sites for the Pokot People.

14. (2015) Kenya National Bureau of Statistics. 